\title{
NETWORK ANALYSIS APPROACH \\ TO STROKE CARE AND ASSISTANCE \\ PROVISION: AN EMPIRICAL STUDY
}

pages: $32-37$

\author{
NiNA SZCZYGIEL, SILVINA SANTANA
}

\begin{abstract}
A B S T R A C T
To model and analyse stroke care and assistance provision in the Portuguese context from the network perspective. We used the network theory as a theoretical foundation for the study. The model proposed by Frey et al. (2006) was used to elicit and comprehend possible interactions and relations between organisations expected to be involved in the provision of care and assistance to stroke patients in their pathway to rehabilitation. Providers were identified and contacted to evaluate the nature and intensity of relationships. Network analysis was performed with the NodeXL software package. Analysis of 509 entities based on about 260000 entries indicates that stroke care provision in the evaluated context is best captured in the coalition-collaboration setting, which appears to best demonstrate the character of the network. Information from analysis of the collaboration stage was not sufficient to determine the network dynamics. Application of the network theory to understand interorganisational dynamics of the complex health care context. Empirical validation of the model proposed by Frey et al. (2006) in terms of its operationalisation and the way it actually reflects the practical context. Examination and analysis of interorganisational relationships and its contribution to management of compound health care context involving actors from various sectors.
\end{abstract}

KEY WORDS

network analysis, care and assistance provision, stroke

DOI: 10.1515/emj-2017-0011
Corresponding author:

Nina Szczygie

University of Aveiro, Research Unit in Governance, Competitiveness and Public Policies, Department of Economics, Management, Industrial Engineering and Tourism, Portugal e-mail: nina.szczygiel@ua.pt

Silvina Santana

University of Aveiro, Institute of Electronics and Informatics Engineering of Aveiro Research Unit in Governance, Competitiveness and Public Policies, Department of Economics, Management, Industrial Engineering and Tourism, Portugal

e-mail: silvina.santana@ua.pt

\section{INTRODUCTION}

Over last decades, the world has been undergoing changes, which have a more or less immediate and direct impact on the way we are living now. Demographic, socioeconomic and epidemiologic challenges have been putting increasing pressure on policy makers (Pierson, 2006) requiring a shift in the paradigm of care provision. Traditional orientation towards acute care has been challenged to give an appropriate response to multiple chronic and longterm health conditions, the prevalence of which increases with age. The escalation of demand for complex and multidisciplinary care services has requested suggestions of methodologies and tools to improve coordination and continuity of care (Andreasson \& Winge, 2010). 
The elderly population in Portugal represents the largest and the fastest growing population group in the country. It is estimated that between 2005 and 2030, the number of Portuguese aged 65 and above will increase from $16.9 \%$ to $23.3 \%$ and those aged 80 and older will increase from $3.7 \%$ to $6.4 \%$ of the total population (Eurostat, 2008). The conditions in place to deal with this scenario are not promising. The economic and financial crisis has led to economic stagnation, insolvencies and a wave of emigration. Labour market participation among Portuguese women is currently one of the highest in the European Union (Eurostat, 2010), affecting the capacity of informal care provision.

The World Health Organisation (WHO) reports 15 million cerebrovascular accident cases annually (Mackay \& Mensah, 2004) causing 5 million deaths. In Portugal, stroke accounts for three deaths per hour (Sá, 2009). To survivours, it is an important factor leading to disability and dependency in activities of daily living (Moutinho et al., 2013) with high costs to the patient, relatives and care systems (WHO, 2010), and a source of physical and emotional burden. Stroke is a vital issue in public health policy (Truelsen et al., 2006) and requires a collaborative approach to patient-centred care provision.

Structures of care provision in Portugal exist under the Ministry of Health responsible for health care services and the Ministry of Labour and Social Solidarity, responsible for social benefits, such as pensions, unemployment and incapacity benefits. Ideally, the systems should be complementary. In the case of a stroke patient, the network of care may consist of a range of entities: hospitals, rehabilitation units of different types, health centres, Social Security (a relevant source of information about financial support for patients and families), Private Institutions of Social Solidarity (IPSS, non-profit organisations directly providing a large part of social and family services), Misericórdias (charitable organisations operating according to Catholic principles with an important role in social assistance to the community), religious entities (moral, financial and material support), city and parish councils (expected to provide for instance technical support), fire departments (offering transportation services on the basis of cooperation agreements), and physiotherapy clinics and other private service providers relevant to the patient (e.g. gyms). Some of these entities operate within the National Network of Integrated Continuous Care (RNCCI), a network created in 2006 that combines teams providing long-term care, social support and palliative activity with its origins in community services (Barros \& Simões, 2007). The network comprises convalescence units, medium-term care and rehabilitation units, long-term care and maintenance units, palliative care units, and day care and autonomy promotion. It promotes coordination between different institutions of care, with early referrals and patient's condition monitoring.

This paper addresses the examination of the structure of stroke care and assistance provision in the Portuguese context with the use of the network theory and analysis. It is organised as follows. Section 1 presents a short literature review regarding the network theory and network analysis introducing appropriate metrics to be used. Section 2 describes research methods. Section 3 presents results of our study, which are then discussed in Section 4. The final section provides conclusions and implications.

\section{LITERATURE REVIEW}

The basic sociological concept of a network was given by Mitchell (1969) as a specific type of relationship (ties) that links a group of people, objects or events (vertices or nodes). A network is hence composed of ties and nodes and aims to depict some relationships between the nodes. The network theory is a formal theory that when applied to the organisational domain is based on the assumption that organisations operate in the market through interdependence built upon mutual relationships.

Network analysis is a set of techniques developed to study how individuals, groups, organisations and communities connect and interact with each other (Wasserman \& Faust, 1994). It focuses on the analysis of patterns of relationships between the network elements and the way these patterns can be used to value processes and performance. A variety of measures drawn from network analysis literature has been used to uncover patterns within the social structure.

Network density is the average strength of connections among units in the network or a proportion of ties which are present relatively to those which are possible in a certain setting and is one of the most common indices of the network structure. It permits the assessment of the solidity of the network and the verification of the presence of subgroups (Palazzolo et al., 2011).

A great amount of recent research on networks has focused on centrality patterns that emphasise 
a relative position of nodes within the network. Freeman (1979) has concentrated on different types of centrality and presented a relevant conceptual review of degree-based measures, betweenness and closeness. The basic approach to degree-based measures is network size and communication activity. Degree centrality is based on some direct ties of the vertex. Betweenness centrality is an indication of the strategic importance of actors within the network and points out the capacity to control the network or disrupt communication. Higher betweenness centrality indicates that fewer actors provide bridging roles across the network (Lewis, 2005). Closeness centrality refers to the extent to which an individual part of the network can reach all other members of the network in the fewest number of direct and indirect connections. Closeness measures reveal individual autonomy and freedom from the control of others. Direct links are considered 'closer' than indirect (Brass, Butterfield \& Skaggs, 1998). Density and centrality are important complementary measures.

The potential of network analysis application to health and social care system interactions is yet to be reached (Luke \& Harris, 2007). The literature describes some networks in health and social care focusing on interventions addressing public health matters, especially about common issues such as determinants of health. Rutten and Boekema (2004) argue that nowadays health and social care organisations act similarly to those of other sectors and perceive the collaborative environment as a way to exchange knowledge, skills and build synergies. Therefore, network theory and analysis seem a promising approach to the study such complex arrangements.

\section{RESEARCH METHODS}

The present research was carried out as a part of a larger study which involved the evaluation of a range of aspects of the stroke care network from both the demand and supply sides. The first phase of the study (the demand side) was done within the Portuguese branch of HOMECARE (Clinical Continuity by Integrated Care) EU-funded project [FP7Homecare 222954] that has validated an early home supported discharge procedure for stoke patients through a randomised controlled trial (Santana et al., 2016). The second phase of the study (the supply side) involved stroke care and assistance providers in the district of Aveiro who were asked to appraise the network from their perspective. Care providers were identified through a comprehensive search starting with those identified earlier by the patients admitted to the HOMECARE trial and then by use of miscellaneous sources. The snowballing method was used to gather information on entities less accessible through general databases (e.g. physiotherapy clinics).

Identified entities were listed and contacted over the phone to confirm their current situation (active/ inactive) and services they provided (whether adequate for stoke patients). Each organisation that agreed to participate in the study was requested to assess its relationships with other members of the network. The data collection took four months (March-July 2014).

The model proposed by Frey et al. (2006) was used as a framework to organise data on nature and strength of relationships between stroke care and assistance providers. It was considered the most suitable as other available models were either too restricted or too broad. Besides networking (stage 1), cooperation, coordination, coalition and collaboration (stages 2 to 5, respectively), Frey et al. (2006) recognise that no interaction might exist between entities.

Data analysis was performed with the NodeXL version 1.0.1.332 software. NodeXL is a network analysis software package integrated into Microsoft Excel 2007, 2010, 2013 and 2016. It intends to collect data in a format of class libraries and to analyse and visualise them in an output of networks.

\section{RESEARCH RESULTS}

The analysis was performed on the database consisting of 509 vertices representing entities effectively providing care and assistance to stroke patients in the district of Aveiro. For all identified relationships, there were 58559 edges that connected the vertices. The database demonstrating the strength of linkages between each entity in the study contained circa 260000 entries. Graphs were laid out using the Fruchterman-Reingold layout algorithm.

The strategy for the analysis was to gradually eliminate the weakest relationships. The analysis started with the global network and evaluated remaining configurations, systematically removing lower levels of interaction. The number of entities 
Tab. 1. Metrics of the relationship settings

\begin{tabular}{|l|r|r|r|r|}
\hline \multicolumn{1}{|c|}{ SETTING } & $\begin{array}{c}\text { IN-DEGREE } \\
\text { AND OUT- } \\
\text { DEGREE MEAN }\end{array}$ & $\begin{array}{c}\text { BETWEENNESS } \\
\text { CENTRALITY } \\
\text { MEAN }\end{array}$ & $\begin{array}{c}\text { CLOSENESS } \\
\text { CENTRALITY } \\
\text { MEAN }\end{array}$ & $\begin{array}{c}\text { GRAPH } \\
\text { DENSITY }\end{array}$ \\
\hline $\begin{array}{l}\text { Networking- } \\
\text { collaboration } \\
\text { (global network) }\end{array}$ & 198.33 & 186.99 & 0.001 & 0.39 \\
\hline $\begin{array}{l}\text { Cooperation- } \\
\text { collaboration }\end{array}$ & 28.14 & 649.04 & 0.001 & 0.06 \\
\hline $\begin{array}{l}\text { Coordination- } \\
\text { collaboration }\end{array}$ & 7.19 & 842.96 & 0.007 & 0.02 \\
\hline $\begin{array}{l}\text { Coalition- } \\
\text { collaboration }\end{array}$ & 1.23 & 12.91 & 0.145 & 0.006 \\
\hline
\end{tabular}

Source: authors' elaboration based on (Frey et al., 2006).

decreased from 509 in the global network to 222 in the coalition-collaboration setting and 44 in the collaboration setting. Table 1 presents network metrics of the analysed settings. Means of in-degree (number of connections to a vertex, that is, the number of links in the direction of an institution) and out-degree (number of connections toward other vertices, that is, directed to other institutions of the network) fell from 198.33 in the global setting to 1.23 in the coalitioncollaboration setting. In the global network, there were about 175 institutions which did not contact any other institution. This ratio increased in the coordination-collaboration setting (340 from 483). In the coalition-collaboration setting, there were still about 100 from 222 that did not contact any other institution.

In the setting of the highest relationship intensity, 35 from 44 institutions indicated to have only one connection with other members of the network. There were three major entities of similar degree and centrality, all of them city councils. These three nodes formed a group of a relatively high influence. The first had 11 connections and the second -8 connections; the last one was less 'central'. Parish councils and IPSS were the most present entities at this stage. Hospital Infante D. Pedro, the central hospital in the district of Aveiro, where the stroke unit was located, was not considered by the network members as a highly collaborating entity. The network characteristics in the collaboration setting, given the number of members and type of relationships, affected the potential of further analysis.

As betweenness centrality has no limits, the metric values were compared among considered configurations. Along the process of decreasing the number of linkages and limiting relationships to a more intense nature, mean of betweenness centrality increased to substantially drop in the coalition-collaboration configuration. In that setting, just a few entities had strong connections. These presented highest betweenness centrality what made them the 'closest' to all other nodes. Still, the degree centrality was low (21 connections with other institutions of the most connected city council). Vertices with high betweenness centrality are frequently located at the crossing of two or more high dense network groups. This is an indication that at the coalition-collaboration level, the structure of the network meaningfully changed in terms of connectivity between institutions.

The closeness centrality remained very low through the configurations. One characteristic of this metric is attributing high scores to nodes located near the centre of local constellations of nodes, that is, local communities, within the overall network. The results clearly point out the continuous high density of the network and a close distance from the centre of the group. The graph density, as a proportion of existing ties to possible ties, has decreased with eliminating weaker relationships, reaching 0.006 in the coalition-collaboration setting.

\section{DISCUSSION OF THE RESULTS}

Social relationships in Portugal have been strongly marked by economic factors and the cultural shift leading to social disintegration and affecting informal care capacity in a context where it is increasingly needed. The care system is under pressure to respond to comprehensive needs as well as organise resources and processes of care provision around a patient. As a result, the RNCCI was launched in 2006 as a formal organisational model providing integrated health and welfare services in a situation of dependency and autonomy failure. Other diseasespecific or issue-specific programmes of a more limited scope have also been implemented.

Collaborative action is perceived as an opportunity to create competitive advantages and has received increasing attention over last years (Lim \& Tang, 2000). Relations of collaborative nature among organisations within and between sectors have been 
a subject of interest of health and social care (Greenwald, 2008) and seen as a reasonable response to comprehensive care needs. The intersectoral level is characterised by particular complexities, such as community approval, assuming commitment, structures and processes, and adequate control and evaluation measurements (Kreisel \& Schrinding, 1998).

Network analysis application in social sciences is a proof of a shift from the traditional individualism towards structural analysis (Garton, Haythornwaite \& Wellman, 1999). From typical units, such as elements and their attributes, the focus is changing to the type and structure of the underlying relation. With the network theory and network analysis, we were able to apply and empirically validate the model proposed by Frey et al. (2006) capturing existing interactions between stroke care and assistance providers.

Network analysis application in the context of stroke care and assistance has revealed providers' perceptions of existing linkages. The coalition-collaboration setting has appeared the most suitable to reflect the network dynamics. Understanding the structure and patterns of interactions between providers can bring rich and valuable insights to the process of management of complex health care context within intersectoral perspective.

The applied model seemed to cover aspects of interorganisational relationships adequately to the complexity of care and assistance needs springing from long-term and chronic health conditions. However, we do acknowledge some challenges we faced. Despite the provided short explanation, the coalition phase was identified as confusing to care and assistance providers. Another issue was related to collaboration, which Frey et al. (2006, p. 387) specified as a level, on which 'consensus is reached on all decisions' and 'members belong to one system'. A term suggested as more suitable to that description was 'integration'. In a multiple-setting and networked multi-agent context towards which the current care systems are tending, this approach may be, however, infeasible and unmanageable as not all systems, organisations or services can be integrated.

\section{CONCLUSIONS}

An enormous increase of chronic and long-term conditions in last decades is a global phenomenon calling for substantial organisational shifts in care provision and proposing methodologies that would reflect this new reality. With a complex nature at the system, organisational and individual levels, effective provision of care and assistance services requires formal recognition and a strategic adaptation of multiple action agendas. Network analysis brings an interesting methodological perspective into the multi-stakeholder and cross-sectoral setting and offers practical implications. Practice based on robust and coordinated interactions could result in better health outcomes, provide a better quality of care and enhance patient satisfaction.

\section{ACKNOWLEDGEMENTS}

The paper is a result of research conducted in two phases of which the data for phase one were collected within the Portuguese branch of HOMECARE (Clinical Continuity by Integrated Care) EU-funded project [FP7-Homecare 222954]. NS acknowledges the support of the FCT - the Portuguese Foundation for Science and Technology [grant number SFRH/BD/69892/2010].

\section{LITERATURE}

Andreasson, S., \& Winge, M. (2010). Innovations for sustainable health and social care: Value-creating health and social care processes based on patient need. Stockholm, Sweden: Swedish Governmental Agency for Innovation System.

Barros, P., \& Simões, J. (2007). Health system review. Health Systems in Transition, 9(5), 1-140.

Brass, D. J., Butterfield, K. D., \& Skaggs, B. C. (1998). Relationships and unethical behavior: A social network perspective. The Academy of Management Review, 23(1), 14-31.

Eurostat. (2008). Population Statistics. Retrieved from http://epp.eurostat.ec.europa.eu/portal/page/portal/ population/data/database

Eurostat. (2010). Europe in figures. Eurostat yearbook 2010. Retrieved from http://ec.europa.eu/eurostat/documents/3217494/5721265/KS-CD-10-220-EN.PDF/ e 47b 231 c-c $411-4 d 4$ e- 8 cd 6 -e 0257 be 4 f 2 e 6 ? version $=1.0$

Freeman, L. C. (1979). Centrality in social networks: Conceptual clarification. Social Networks, 1, 215-239.

Frey, B. B., Lohmeier, J. H., Lee, S. W., \& Tollefson, N. (2006). Measuring collaboration among grant partners. American Journal of Evaluation, 27(3), 383-392.

Garton, L., Haythornwaite, C., \& Wellman, B. (1999). Studying on-line social networks. In S. Jones (Ed.), Doing Internet Research. Thousand Oaks, USA: SAGE Publications Inc. 
Greenwald, H. P. (2008). Challenges in cross-sectoral partnerships: An organizational perspective. Consortium on Collaborative Governance (CCG) Mini-Conference. Retrieved from http://www.serviceleader.org/sites/ default/files/file/Challenges\%20in\%20Cross-Sector\%20Partnerships, \%20Greenwald.pdf

Kreisel, W., \& von Schrinding, Y. (1998). Intersectoral action for health: A cornerstone for health for all in the twenty-first century. World Health Statistics Quarterly, 51(1), 75-78.

Lewis, J. M. (2005). A network approach for researching partnerships in health. Australia and New Zealand Health Policy, 2(22).

Lim, P. C., \& Tang, N. K. H. (2000). A study of patients' expectations and satisfaction in Singapore hospitals. International Journal of Health Care Quality Assurance, 13(7), 290-299.

Luke, D., \& Harris, J. (2007). Network analysis in public health: History, methods, and applications. Annual Review of Public Health, 28, 69-93.

Mackay, J., \& Mensah, G. (2004). The atlas of heart disease and stroke. Geneva, Switzerland: World Health Organization.

Mitchell, J. C. (1969). The concept and use of social networks. In J. C. Mitchell (Ed.), Social Networks in Urban Situations, (pp. 1-44). Manchester, England: Manchester University Press.

Moutinho, M., Magalhães, R., Correia, M., \& Silva, M. C. (2013). Avaliação da via verde do acidente vascular cerebral de Portugal: Caracterização e prognóstico dos utilizadores [Evaluation of the green pathway of stroke in Portugal: Characterization and prognosis of users]. Acta Médica Portuguesa, 26(2), 113-122.

Palazzolo, M., Grippa, F., Booth, A., Rechner, S. Bucuvalas, J., \& Gloor, P. (2011). Measuring social network structure of clinical teams caring for patients with complex conditions. Procedia - Social and Behavioral Sciences, 26, 17-29.

Pierson, C. (2006). Beyond the welfare state?: The new political economy of welfare. Cambridge, England: Polity Press.

Rutten, R. P. J. H., \& Boekema, F. W. M. (2004). The spatial dimension of inter-firm learning: Case study and conceptualization. In: P. H. Cooke, A. Piccaluga (Eds.), Regional Economies as Knowledge Laboratories. Cheltenham, England: Edward Elgar.

Sá, M. J. (2009). AVC - primeira causa de morte em Portugal [AVC - the leading cause of death in Portugal]. Revista da Faculdade de Ciências da Saúde, 6, 12-19.

Santana, S., Rente, J., Neves, C., Redondo, P., Szczygiel, N., Larsen, T., Jepsen, B., \& Langhorne, P. (2016). Early home-supported discharge for patients with stroke in Portugal: A randomized controlled trial. Clinical Rehabilitation, 31(2), 197-206.

Truelsen, T., Piechowski-Jozwiak, B., Bonita, R., Mathers, C., Bogousslavsky, J., \& Boysen, G. (2006). Stroke incidence and prevalence in Europe: A review of available data. European Journal of Neurology, 13(6), 581-598.

Wasserman, S., \& Faust, K. (1994). Social network analysis: Methods and applications. New York, USA: Cambridge University Press.
World Health Organization. (2010). Portugal. Health system performance assessment. Retrieved from http://www. euro.who.int/__data/assets/pdf_file/0006/131766/ E94518.pdf?ua=1 